\title{
ABNORMAL PATTERN OF RENAL AND GONADAL VEINS AND ITS DEVELOPMENTAL CORRELATION
}

\author{
Krishna Gopal *1, Onkar Singh ${ }^{2}$, Anurag ${ }^{3}$.
}

${ }^{{ }_{1}}$ Associate Professor, Department of Anatomy, Sri Guru Ram Rai Medical College And Hospital, Patel Nagar, Dehradun. Uttaranchal, India.

${ }^{2}$ Demonstrator, Department of Anatomy, Sri Guru Ram Rai Medical College And Hospital, Patel Nagar, Dehradun. Uttaranchal, India.

${ }^{* 3}$ Professor and Head, Department of Anatomy, Sri Guru Ram Rai Medical College And Hospital, Patel Nagar, Dehradun. Uttaranchal, India.

\section{ABSTRACT}

Introduction: The variations of the renal veins are not as common as arteries. The renal veins are formed near the hilum by the union of interlobar veins in front of the renal artery. Variant anatomy can pose a problem at both organ recovery and implantation.

Materials and Methods: This study included thorough dissection of 25 cadavers obtained from department of Anatomy, Sri Guru Ram Rai Institute of medical and health sciences Dehradun following standard guidelines. All the Variation of the right and left gonadal veins and renal veins were observed and reported.

Results: Out of 25 cadavers dissected in present study, the accessory renal veins was encountered in 5 (20\%) cadavers in right side. one cadaver (4\%) the right gonadal vein drains at the junction of right accessory renal vein and inferior vena cava. The right gonadal vein drains into the right renal vein in two (8\%) cadavers and it also drains into the left renal vein in one cadaver (4\%).

Conclusion: The numerous variations like presence of accessory renal vein, abnormal drainage of gonadal veins were observed in this study. Incidence of variations of testicular veins was noted mostly on the right side. These variations are of clinical significance are very useful for the anatomists, radiologists, anesthesiologists, and general surgeons.

KEY WORDS: Accessory renal vein, gonadal vein, anatomical variations.

Address for Correspondence: Dr. Krishna Gopal, Associate Professor, Department of Anatomy, Sri Guru Ram Rai Medical College And Hospital, Patel Nagar, Dehradun. Uttaranchal, India.

E-Mail: drkrish2007@gmail.com

\section{Access this Article online}

\section{Quick Response code}

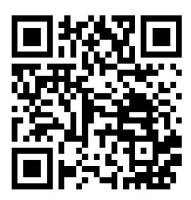

DOI: $10.16965 /$ ijar.2017.316

Web site: International Journal of Anatomy and Research ISSN 2321-4287

www.ijmhr.org/ijar.htm

Received: 22 June 2017

Peer Review: 22 June 2017

Revised: None
Accepted: 03 Aug 2017

Published (O): 31 Aug 2017

Published (P): 31 Aug 2017

\section{INTRODUCTION}

Renal vessels are known with a wide range of variations that have also been evidenced during live kidney donor work-up in recent years. Most of these variations may otherwise have no clinical signifi-cance other than the surgery for lapa-roscopic donor nephrectomy. These variations can lead to significant surgical complications or even life-threatening events. The renal veins are formed near the hilum by the union of interlobar veins in front of the renal artery. Each kidney is drained by a single renal 
vein into the inferior vena cava at the level of $\mathrm{L} 2$ vertebra. The right renal vein is shorter (2-4 $\mathrm{cm})$ than the left $(6-10 \mathrm{~cm})$. It receives blood only from the right kidney, whereas the left renal vein receives the left adrenal and gonadal veins in addition to the vein coming from the kidney. It were reported that the presence of renal arterial abnormalities predominates the venous abnormalities. Variant anatomy can pose a problem at both organ recovery and implantation. Variations in the origin, course \& termination of renal veins, mainly resulting from the errors of the embryological development, are frequently observed [1].

In an era of renal transplantation and changing trend in favor of conservative renal surgery, the knowledge of the anatomy and variational patterns of renal veins is important for such surgeries.

Development: The kidneys arise from the metanephros in the developing embryo [2] and as the embryo grows, the kidneys migrate cranially from the pelvis to the normal position, and at the same time undergo a $90^{\circ}$ axial rotation from horizontal to medial, while the hilum rotates from its anterior facing position to a medial facing one. The development of the renal veins is a complex process with many possible alternative patterns of formation. This is particularly true on the left side because of the communication of the left renal vein with the adrenal, gonadal, phrenic and hemiazygos veins. As per literature [3] and available data right testicular vein develops from lower part of right sub cardinal vein. Gonadal vein develops from caudal part of subcardinal vein and it drains into the suprasubcardinal anastomosis. In the right side, this supra-subcardinal anastomosis and also a small portion of Subcardinal vein are incorporated into the formation of inferior vena cava, so right gonadal vein usually drains into the inferior vena cava. Embryologically, the bilateral symmetrical cardinal venous system becomes a unilateral right sided inferior vena cava. Initially two renal veins are present on each side at the ventral and dorsal plane. Convergence of both tributaries results in the single vessel formation. Persistence of these two veins leads to the presence of accessory or additional renal veins [4].

\section{MATERIALS AND METHODS}

The present study was undertaken on twenty five adult embalmed cadavers of known sex, obtained from department of Anatomy, Sri Guru Ram Rai Institute of medical and health sciences Dehradun. The abdominal cavity was opened and abdominal viscera were systemically removed according to Cunningham manual of practical Anatomy. The testicular veins were traced from the testis to their termination into the Inferior vena cava and left renal vein. All the Variation of the right and left testicular veins and accessory renal veins were observed and the photographs were taken with the help of digital camera.

\section{RESULTS}

In the present study, the accessory renal veins were seen on right side in 5 cadavers [Table-1/ Fig-1] and none on the left side. In these cases, the right renal vein opened into the inferior vena cava opposite to the left renal vein. Normally the left gonadal vein drains into the left renal vein and right gonadal vein drain into the inferior vena cava, but in our observation, in one cadaver the right gonadal vein drains at the junction of right accessory renal vein and inferior vena cava [Table-1/Fig-1]. Out of 25, in two cadavers the right gonadal vein directly drains into the right renal vein [Table-1/Fig-2]. It was also observed that the right gonadal vein drains into the left renal vein in one cadaver instead of inferior vena cava [Table-1/Fig-3].

Fig. 1: Showing right gonadal vein drains at the junction of accessory renal vein and inferior vena cava.

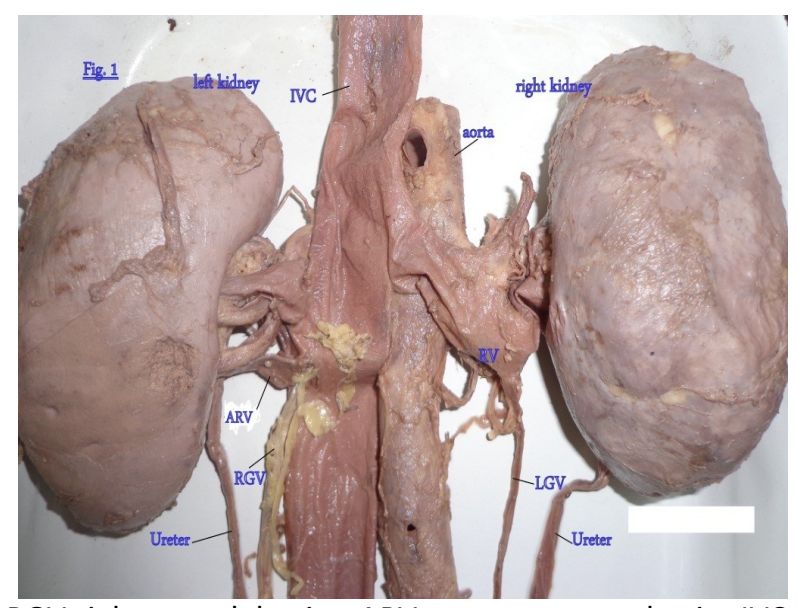

RGV-right gonadal vein, ARV- accessory renal vein, IVCinferior vena cava, RV-right renal vein, LGV-left gonadal vein. 
Fig. 2: Showing right gonadal vein drains into the right renal vein .RGV-right gonadal vein.

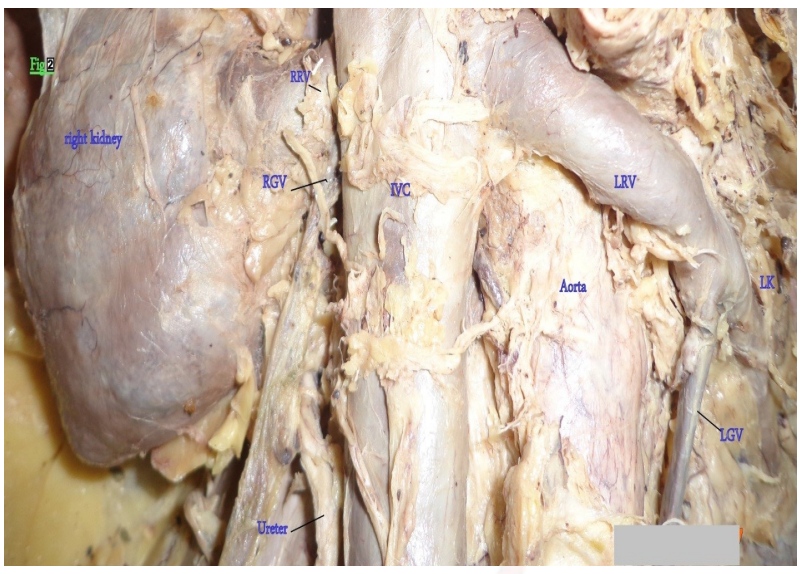

LRV- left renal vein, IVC-inferior vena cava, RRV-right renal vein, LGV-left gonadal vein, LK- left kidney.

Fig. 3: Showing right gonadal vein drains into the left renal vein.

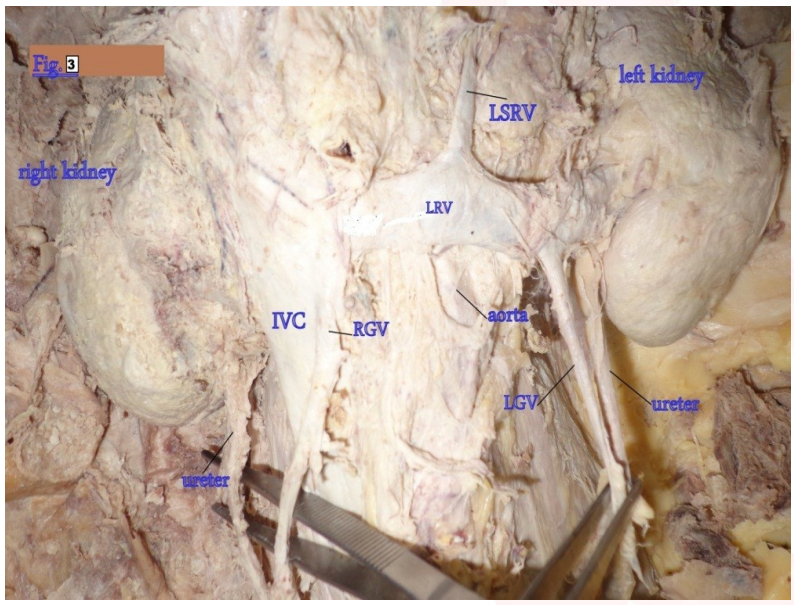

RGV-right gonadal vein, LRV- left renal vein, IVC-inferior vena cava, , LGV-left gonadal vein, LSRV-left suprarenal vein.

Table 1: Different variations revealed in present study. IVC- Inferior vena cava, RGV- Right gonadal vein, RRVRight renal vein, LRV- Left renal vein.

\begin{tabular}{|c|c|c|c|}
\hline Sr. no. & Variations & $\begin{array}{c}\text { No. of } \\
\text { cadavers }\end{array}$ & Percentage \\
\hline 1 & Right accessory renal vein & 5 & $20 \%$ \\
\hline 2 & RGV drains at the junction of IVC \% ARV & 1 & $4 \%$ \\
\hline 3 & RGV drains into the RRV & 2 & $8 \%$ \\
\hline 4 & RGV drains into LRV & 1 & $4 \%$ \\
\hline
\end{tabular}

\section{DISCUSSION}

The normal testicular vein, the renal vein and the inferior vena cava segments into which the gonadal vein drain, have a common origin in the fetal subcardinal vein.

Bergman, Afifi and Miyauchi (2004) [5] mentioned that the gonadal vein can receive as tributary the duodenal vein or the suprarenal vein and included the gonadal veins as non-usual tributaries of the hemiazygos vein. In our study the presence of accessory renal vein were observed in $20 \%$ cases on the right side. Satayapal [6] reported that incidence of additional right renal vein was $26 \%$ as compare to $2.6 \%$ on the left side while Pick \& Anson [7], 1940 reported it in $27.4 \%$ on the right side. Pollok et al [8] also observed that accessory renal vein and other venous variations are more common on the right side. Variations of gonadal veins were more frequent on the left side, as observed by Asala et al (2001) [9]. According to Gay et al [10]. $40 \%$ of patients present multiple gonadal veins. Variations of number of left side gonadal vein and their mode of termination are frequent [11]. Our findings are also suggested that right side venous variations are more common than left. These anomalies of renal veins are associated with the development of the vena cava from the different parts of the cardinal veins of the embryo $[12,13]$. Accessory renal vein has named any extra vein other than renal vein emerging out of kidney and draining separately in the Inferior Vena Cava as.

It was earlier reported that there were tenfold increases in the number of additional renal vein in the right side as compared to that of the left side side [14]. Anomalous multiple renal veins is a contraindication for donor nephrectomy because this anomaly is associated with a higher risk of thrombosis of the graft renal vein ${ }^{15}$. Right testicular vein draining into right renal vein rather than inferior vena cava was reported in 2 out of 150 cadavers dissected by Asala et al, (2001). Bergman found right gonadal vein draining in the right renal vein in $1.5 \%$ ( 4 out of 220 cases). It is revealed in $2 \%$ cases in our study. Our finding is nearer to study of Bergman. In our study It were also found that in one cadaver the right gonadal vein drains at the junction of inferior vena cava and additional renal vein ( accessory renal vein). Such type of finding has been rarely reported earlier. Variations in the terminations of the testicular veins have also been reported. Nayak et al. [16], has found terminal bifurcation of the single right testicular vein into two, each opening into IVC. In another study, right testicular vein showed an abnormal termination in right renal vein instead of inferior vena cava [17].

But in our study such type of variations were not 
found in any cadaver. During dissection it were also observed in one case, that on the right side, the gonadal vein drained directly into the left renal vein instead of inferior vena cava. This type of variation has not been reported earlier. Gupta et al [18] explained that Complex embryogenesis involves the shifting of venous arrangement to the right possibly discouraging any retention of accessory left sided renal veins. Thus rightsided anatomical variations of the renal vein are more common. These variations can lead to significant surgical complications or even life threatening events if un recognized.

\section{CONCLUSION}

In the present study we were found the incidence of presence of accessory right renal vein drain into the inferior vena cava. It were also revealed that the right gonadal vein drain into the right renal vein or the left renal vein instead of inferior vena cava. Incidence of variations of testicular veins was noted mostly on the right side. Anatomical knowledge of the presented variants is of great importance for the appropriate selection of operative techniques during surgical interventions as well as for postoperative management.

\section{ACKNOWLEDGEMENTS}

I am grateful to Dr. Alok chaudhary for her unfailing support and professional insight in the preparation of this article. I also thank the staff members of department of anatomy for assisting in the study.

\section{Conflicts of Interests: None}

\section{REFERENCES}

[1]. Rupert RR. Further study of irregular kidney vessels as found in one hundred eighteen cadavers. Surg Gynaecol Obset .1915;21:471-80.

[2]. Rosenblum ND. Developmental biology of the human kidney. Semin Fetal Neonatal Med 2008;13:125-132.

[3]. McClure CFW, Butler EG, The development of the vena cava inferior in man: Am J Anat 1925;35:331.

[4]. Mankhause WS and Khalique A. The adrenal and renal mass and their connection with Azygos and lumber vein. J Anat. 1986;146:105-15.
[5]. BERGMAN, RA., AFIFI, AK. and MIYAUCHI, R. Illustrated encyclopedia of human anatomic variation: opus II: cardiovascular system: veins: abdomen gonadal veins. 1992-2004.

[6]. Satyapal, K.S. Additional renal vein: incidence and morphometry. Clinical Anatomy, 1995;8:5-55

[7]. Pick, J. W. and Anson. Inferior Phrenic Artery: origin and suprarenal branches. Anat. Rec.1940;78:413427.

[8]. Pollack, R, Prusak BF and Mozes MF. Anatomic abnormalities of cadaver kidneys procured for purpose of transplantation. Am. Surgeon.1986;52:233235.

[9]. Asala S., Chaudhary SC, Masumbuko-Kahamba $\mathrm{N}$,Bidoms M. Anatomical variations of human testicular blood vessels. Annals of Anatomy. 2001;183(6): 545-9.

[10]. Gay SB, Armestead JP, Weber ME, Williamson BR. Left Infrarenal Region: anatomic variants, pathologic conditions, and diagnostic pitfalls. Radiographics. 1991;11(4):549-70.

[11]. Wishahi MM. Detailed anatomy of the internal spermatic vein and the ovarian vein.Human cadaver study and operative spermatic venography: clinical aspects. J Urol. 1991;145:780-84.

[12]. Chuang VP, Mena CE, Hoskins PA. Congenital anomalies of the inferior vena cava. Review of embryogenesis and presentation of a simplified classification. Br J Radiol 1974;47:206-213.

[13]. Mathews R, Smith PA, Fishman EK, Marshall FF. Anomalies of the inferior vena cava and renal veins: Embryologic and surgical considerations. Urology 1999; 53: 873-880.

[14]. Biswas S, Chattopadhyay JC, Panicker H, Amblagan J, Ghosh SK. Variations in renal and testicular veinsA case report. J. Anat. Soc. India. 2006 Dec;55(2):6971.

[15]. Holden A, Smith A, Dukes P, Pilmore H, Yasutomi M. Assessment of 100 live potential renal donors for laparoscopic nephrectomy with multi-detector row helical CT. Radiology 2005;237:973-80.

[16]. Nayak BS, Rao KGM, Shetty SD, Sirasanagandla SR, Kumar N, Guru A. Terminal Bifurcation of the Right Testicular Vein and Left Testicular Arterio-Venous Anastomosis. Kathmandu Univ Med J. 2013;42(2):168-70.

[17]. Holden A, Smith A, Dukes P, Pilmore H, Yasutomi M. Assessment of 100 live potential renal donors for laparoscopic nephrectomy with multi-detector row helical CT. Radiology 2005;237:973-80.

[18]. Gupta R, Gupta A, Aggarwal N. Variations of gonadal vein. J Clin Diagn Res. 2015; 9(2):8-10.384. 